2. To: (Receiving Organization)
Safety Issue Resolution
(SIR)

5. Proj./Prog./Dept./Div.:

Flammable Gas Project

8. Originator Remarks:

For review/approval/issue

11. Receiver Remarks:
11A. Design Basel ine Document?
3. From: (Originating organization) COGEMA Engineering Corp.

6. Design Authority/ Design Agent/Cog. Engr.:

BD Andres

4. Related EDT No.:

$\mathrm{N} / \mathrm{A}$

7. Purchase Order No,

$N / A$

9. Equip./Component No.:

$\mathrm{N} / \mathrm{A}$

10. System/Bldg./Facility:

$$
\text { 241-SY }-101
$$

12. Major Assm. DWg. No.:

$N / A$

13. Permit/Permit Application No.: $\mathrm{N} / \mathrm{A}$

14. Required Response Date:

$$
\mathrm{N} / \mathrm{A}
$$

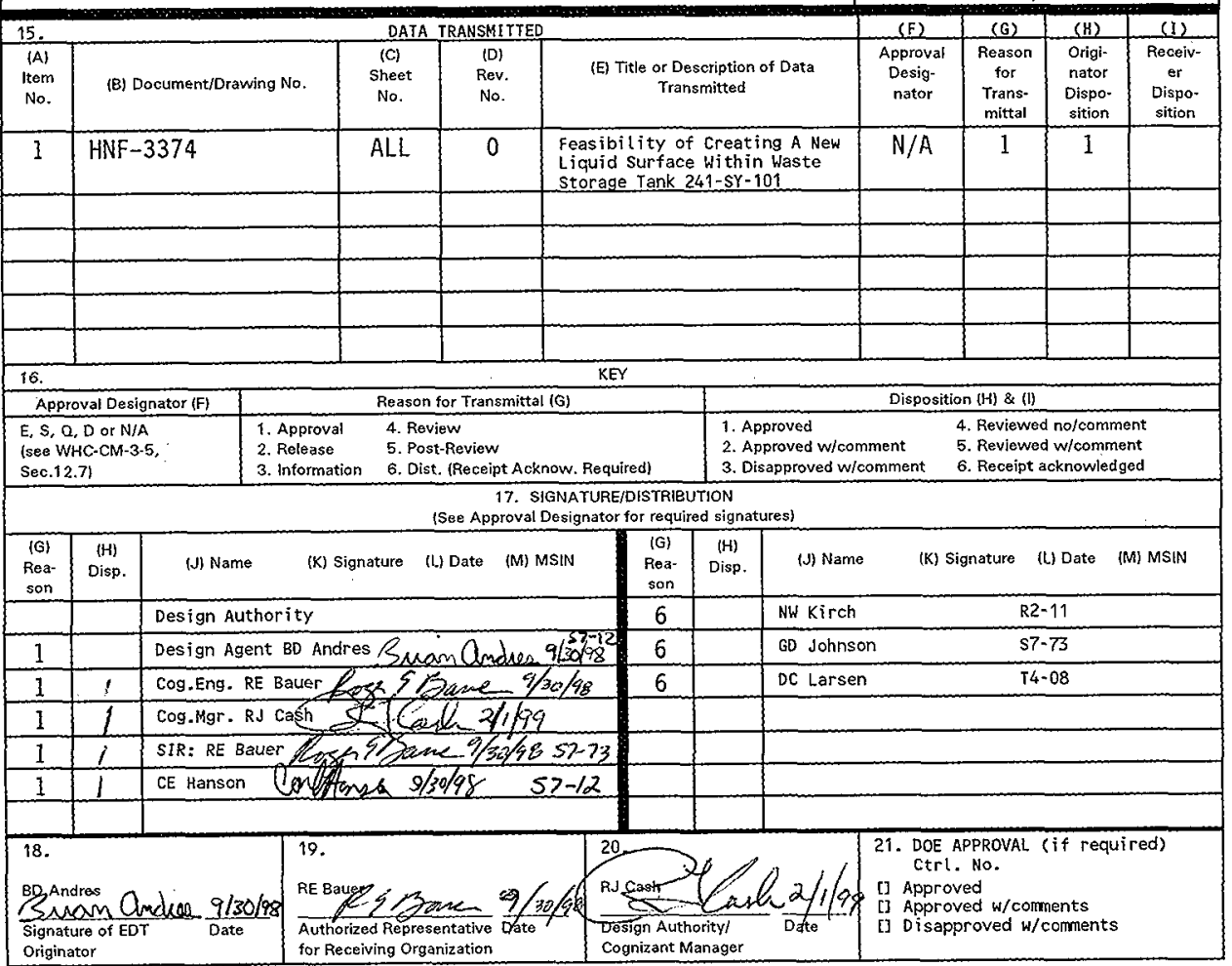

BD-7400-172-2(05/96) GEFO97 


\title{
Feasibility Of Creating A New Liquid Surface Within Waste Storage Tank 241-SY-101
}

\author{
Brian D. Andres
}

COGEMA Engineering Corp., Richtand, WA 99352

U.S. Department of Energy Contract DE-AC06-96RL13200

$\begin{array}{lll}\text { EDT/ECN: } & 623330 & \text { UC: } 2070 \\ \text { Org Code: } & \text { SS180000 } & \text { Charge Code: } 108962 \\ \text { B\&R Code: } & \text { EW3120074 } & \text { Total Pages: } 1900 \mathrm{p}\end{array}$

Key Words: feasibility, study, 241-SY-101, interstitial liquid level (ILL), flammable gas, inventory, hazard, free liquid, mitigation

Abstract: The purpose of this study is to determine the feasibility of creating a new 1 iquid surface within Waste Storage Tank 241-SY-101. This study looked at alternatives for this, as well as providing a summary of observations regarding water lancing results relative to this task.

TRADEMARK DISCLAIMER. Reference herein to any specific commercial product, process, or service by trade name, trademark, manufacturer, or otherwise, does not necessarily constitute or imply its endorsement, recommendation, or favoring by the United States Government or any agency thereof or its contractors or subcontractors.

Printed in the United States of America. To obtain copies of this document, contact: Document Control Services, P.0. Box 950, Mailstop H6-08, Richland WA 99352, Phone (509) 372-2420; Fax (509) 376-4989.
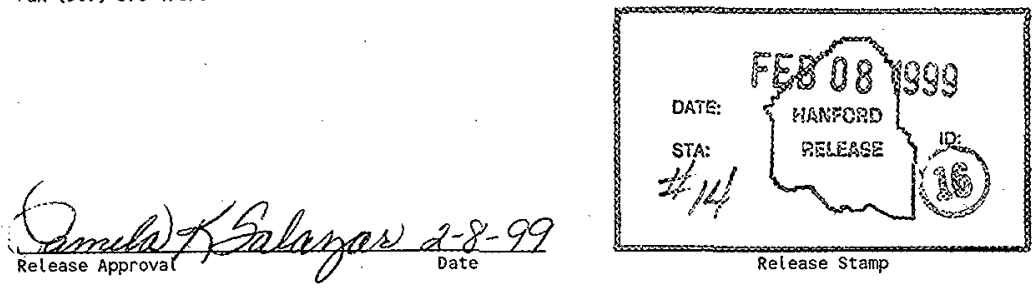
HNF -3374 , Rev 0

\section{FEASIBILITY OF CREATING A NEW LIQUID SURFACE WITHIN WASTE STORAGE TANK 241-SY-101}

SEPTEMBER 1998

PREPARED BY:

BRIAN ANDRES

COGEMA Engineering Corporation 
HNF-3374, Rev 0

TABLE OF CONTENTS

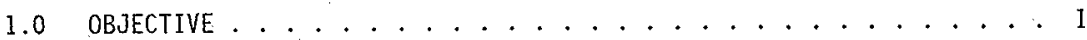

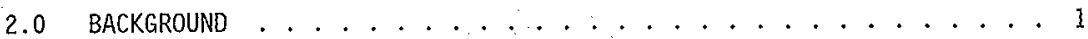

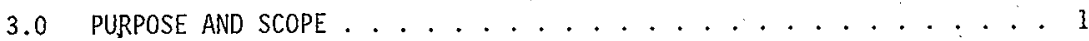

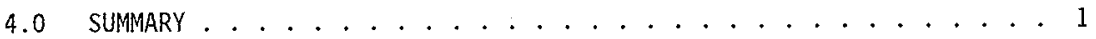

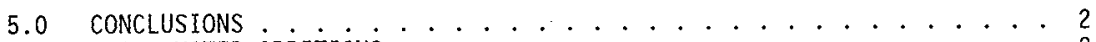

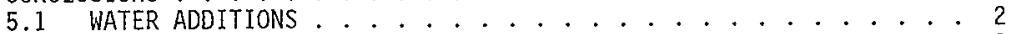

5.2 CONTAINED SYSTEMS . . . . . . . . . . . . . . 2

5.3 HEATING TANK HEADSPACE ............... 3

5.4 USE CONVECTIVE LAYER TO DISSOLVE CRUST ......... 3

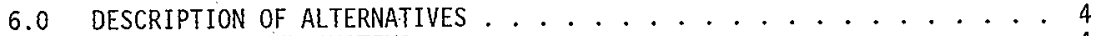

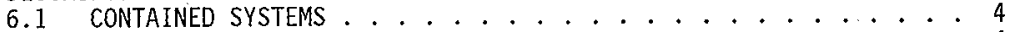

6.1.1 Heating (Contained System) .......... 4

6.1.2 Addition of Less Dense Material ......... 4

6.1 .3 Air Flushing . . . . . . . . . . . 4

6.2 USE CONVECTIVE LAYER TO OISSOLVE CRUST . . . . . . . . . 5

6.2 .1 Mixer Pump Circulation . . . . . . . . . . . 5

6.2 .2 Impel1er Circulator.............. . . 5

6.2 .3 Transfer Pump Circulation . . . . . . . . . 5

APPENDIX A - FIGURES ..................... . . . .

APPENDIX B - PREFERRED ALTERNATIVE COST AND SCHEDULE ........ B-1 


\subsection{OBJECTIVE}

The objective of this study is to investigate the feasibility of creating a new 1iquid surface, within tank 241-SY-101, as a location to measure the tank waste level.

\subsection{BACKGROUND}

Tank 241-SY-101 has exhibited waste level increases and periodic leve? drops associated with the generation, retention and spontaneous release of large quantities of gas since the initial waste additions in the late 1970s. In July 1993, a mixer pump was installed as a method of controlling gas release events. After mixer pump installation the surface level within tank 241-SY-101 remained relatively constant until eariy in 1997 when the surface level began to increase unexpectedly.

Historical1y, changes in the surface level in tank 241-SY-101 have been an indirect measure of retained gas inventory and therefore, an indicator of the flammable gas hazard associated with the tank. The Authorization Basis document specifies operational controls based on tank level.

\subsection{PURPOSE AND SCOPE}

The purpose of this study is to develop concepts for creating an open liquid surface that is in direct communication with the tank liquid so that the level measuring device (ENRAF) measures the liquid level of the tank rather than the crust level. This study focuses on utilizing current measuring devices and does not include other possible options such as using a neutron probe for determining liquid level.

\subsection{SUMMARY}

The four general categories selected for this study are water addition, contained systems, heating tank vapor space, and using a convective layer of tank waste to dissolve the crust. As stated above the primary goal of creating a liquid surface is to provide a location to take liquid level measurements as an indirect measure of retained gas. It is concluded that the most feasible methods for creating a liquid surface all fall under the category of contained systems. A contained heating system is believed to be the most effective way to create and maintain a liquid surface. This conclusion is based on a number of considerations (i.e., cost, schedule, and technical feasibility). but is mainly based on its technical feasibility compared with the other alternatives.

To design, test and install a contained heating system will cost approximately $\$ 645,000$ and take approximately 11 months to complete. The estimated cost and schedule are presented in Appendix $B$. The schedule assumes. a start date of $10 / 1 / 98$ and a start date different from that would move the 
schedule accordingly. Once installed this system has very 1 ittle maintenance. and should have a life expectancy well beyond the retrieval date set for tank SY-101.

Figure 7 in Appendix $A$ is a plan view of tank SY-101 that shows the current status of available risers and what each unavailable riser is designated for. The installation of the contained heating system will require a minimum $8^{\prime \prime}$ diameter riser which is currently available on the multi-port riser assembly.

\subsection{CONCLUSIONS} follows:

Conclusions on the effectiveness of each category studied are as

\subsection{WATER ADDITIONS}

Water additions during lancing and instrument flushing have proven to be an effective method of dissolving the crust. However, it has also been shown that dissolving the crust with water is only a temporary solution to creating a liquid surface. Based on tank waste temperature profiles it is believed the crust could be as thick as $70^{\prime \prime}$ which would require a large quantity of water added on a regular basis to create and maintain a hole for liquid level measurements.

Surface level measurements taken after water additions will be close to the tank liquid surface but not exact. This is because water is less dense than the waste therefore measurements would be of a water surface rather than the Tiquid waste surface. As the crust dissolves the water becomes saturated. and the density becomes equal in a matter of days allowing the crust to reform to its origina? state.

During lancing operations the rising bubbles in the lanced hole cause a pumping effect that 7 ifts the gas-1iquid-solid mixture above the free liquid level, commonly overflowing the waste surface. The foam-like layer stiffens within a day forming fresh crust. Thus current measurements are fundamental $7 y$ incapable of measuring the free 7 iquid level directly. It can only be claimed that a measurement is "near" the free liquid and always somewhat above it."

\subsection{CONTAINED SYSTEMS}

The three contained systems presented in this study include heating, addition of less dense material, and air flushing. Al] three of these methods include maintaining a liquid surface within a pipe that penetrates the surface of the waste and uses a leve? measurement gauge (ENRAF) through the center. Sketches of each of these methods are included in Appendix $A$.

${ }^{1} \mathrm{CW}$ Stewart, 1998, TW598.72, Rev. 0, Waste Leve7 as a Measure of Retained Gas in SY-101, Pacific Northwest National Laboratory, Richland, Washington. 
The addition of heat to dissolve the crust within the pipe is an effective way to create a liquid surface level (Figure 1). The formation of crust on the surface of the waste has a direct correlation to the temperature of the tank headspace. As shown on temperature profiles of the tank the temperature in the headspace is $90^{\circ} \mathrm{F}$ and the waste temperature is $115^{\circ} \mathrm{F}$. When the crust area within the pipe is raised to $115^{\circ} \mathrm{F}$, the crust should dissolve.

A 1iquid surface within the pipe can be formed and maintained by adding a less dense medium (e.g., water) to the surface of the waste (Figure 2). Enough water could be added to form a $5 \mathrm{ft}$ column on top of the waste surface within the pipe creating a liquid surface for measurement. It is believed that water would have to be added periodically in order to maintain the liquid surface.

A Tiquid surface can be maintained by using air to flush any crust buildup out of the pipe (Figure 3 ). There are several possible problems associated with this method. Tank level increases have been observed in the past after air lancing operations, therefore flushing the pipe out through the bottom may contribute to the tank's surface level rise. Also, the quantity of air added to the tank will have to be closeiy monitored to make sure the tank HVAC system can maintain a negative pressure in the vapor space. Another concern is whether the current Notice of Construction and other permits will a] low this, or if they will require modification. The necessary frequency of flushing the pipe is unknown.

An additional feature that can be added to any of the three contained systems is dip tubes. Air can be forced down the dip tube legs creating a mixing effect within the contained column of waste helping to prevent a new crust from forming. Dip tubes also can be utilized as a measuring tool for surface level and waste density. Because the density measurement is representative of the waste between the ends of the dip tubes, the surface level measurement may not be accurate enough to reveal the absolute tank surface level. However, the dip tubes can be a good method for detecting changes in the surface level.

\subsection{HEATING TANK HEADSPACE}

Increasing the tank headspace temperature from $90^{\circ} \mathrm{F}$ to around $115^{\circ} \mathrm{F}$ would tend to dissolve the crust. This would require a large energy input to heat and then to maintain the desired temperature which would not be practical. Heating the tank vapor space would also raise the temperature of the waste which currently has an operational control limit of $135^{\circ} \mathrm{F}$. The major risk of heating is if unwanted chemical reactions or physical changes began, it would take several months to lower the temperature because of the large thermal mass of the waste. This option is not considered feasible.

\subsection{USE CONVECTIVE LAYER TO DISSOLVE CRUST}

Three methods were looked at to transfer waste from the convective layer in the tank to the top of the crust. These methods included mixer pump circulation (Figure 4), impelier circulator (Figure 5), and transfer pump circulation (Figure 6). It is believed that transferring waste to the surface will cause it to solidify once exposed to the headspace temperature and wi7l 
only add to the thickness of the crust. For this reason these methods are not considered to be a feasible way to create a liquid surface leve?.

\subsection{DESCRIPTION OF ALTERNATIVES}

The following is a detailed description of each method listed in this study with the exception of water additions and headspace heating which are general concepts and no specific designs were developed.

\subsection{CONTAINED SYSTEMS}

\subsubsection{Heating (Contained System)}

This method consists of an open-ended pipe that penetrates the waste surface extending several feet below the crust layer. A second, slightly larger, pipe is used to create an air space around the first pipe that is completely sealed off from the waste as shown in Figure 1. A heat transfer system consisting of a pump and heater is placed on a concrete pad above the tank. Tubing that forms coils around the inner pipe allows a heating medium such as glycol to be circulated through the air space heating the waste within the inner pipe. The temperature of the waste within the inner pipe is raised to approximately $115^{\circ} \mathrm{F}$ in order to dissolve the crust and maintain a liquid surface. An ENRAF leveT measuring device is used to monitor surface level within the inner pipe.

\subsubsection{Addition of Less Dense Material}

This method also consists of an open-ended pipe that penetrates the waste surface and extends several feet below the crust. Using a material with a Tesser density than the waste creates a liquid column within the pipe as shown in Figure 2. This will allow the ENRAF to take surface level measurements within the pipe. One medium that can be used is water. If a $6^{\prime \prime}$ diameter pipe is used it would take approximately 7.5 gallons of water to form a 5 foot column within the pipe. Water may have to be added periodically in the event that waste particles migrate up and contaminate the water surface.

\subsubsection{Air Flushing}

This concept aiso utilizes an open-ended pipe to form a contained system that extends down into the waste below the crust layer. As a crust begins to form on the 1iquid surface within the pipe it can be flushed out through the bottom using a surge of air. An ENRAF will take surface level measurements within the pipe. Figure 3 presents the equipment setup for this application. 
HNF-3374, Rev 0

\subsection{USE CONVECTIVE LAYER TO DISSOLVE CRUST}

\subsubsection{Mixer Pump Circulation}

This concept utilizes Hydrogen Mitigation Mixer Pump \#3 (HMR\#3) to circulate waste by transferring it up the column to the pump pit and then discharging it back into the tank on top of the crust as shown in Figure 4. The waste is forced up the column by the $114 \mathrm{ft}$ head produced by the mixer pump in the $2^{\prime \prime}$ flush line that is tied in with the mixer pump plenum. The $2^{\prime \prime}$ flush line exits the mixer pump column in the pump pit where a flexible jumper can be used to connect with equipment that discharges the waste back into the tank through the pump pit $12^{\prime \prime}$ riser.

The HMR\#3 mixer pump has the capability to run for longer periods of time than the currently installed mixer pump because it has a cooling system for the 0i1. This mixer pump also has a nozzle that points up $30^{\circ}$ from the horizontal which may allow for better mixing of the upper portion of the waste in the tank. It is unlikely that the convective waste will dissolve the crust but the circulation of large quantities of waste may help prevent crust from forming in the area of discharge back into the tank.

\subsubsection{Impeller Circulator}

This concept utilizes an open-ended pipe that penetrates the waste surface and extends approximately 20 feet into the waste. Similar to an air lift circulator, an impeller is used to transfer waste up through the pipe to the surface of the crust. This will require a new design of having an impeller mounted on the end of a long shaft driven by a motor and speed reducer as shown in Figure 5.

\subsubsection{Transfer Pump Circulation}

This concept will insert a pump into the tank that transfers waste from the convective layer to the top of the crust as shown in Figure 6 . 
HNF-3374, Rev 0

\section{APPENDIX A}

FIGURES 
HNF -3374 , Rev 0

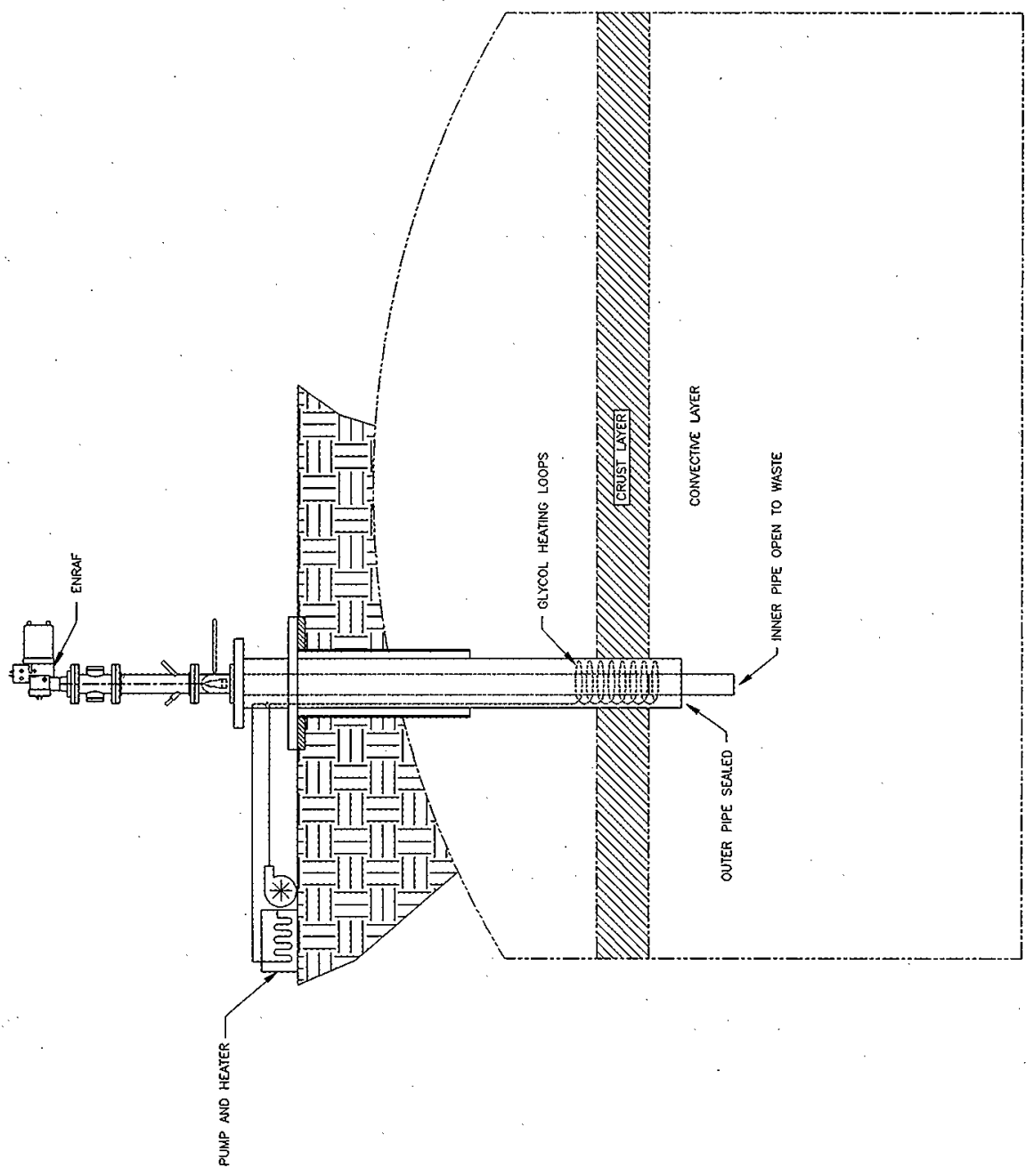

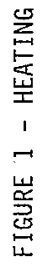


HNF-3374, Rev 0

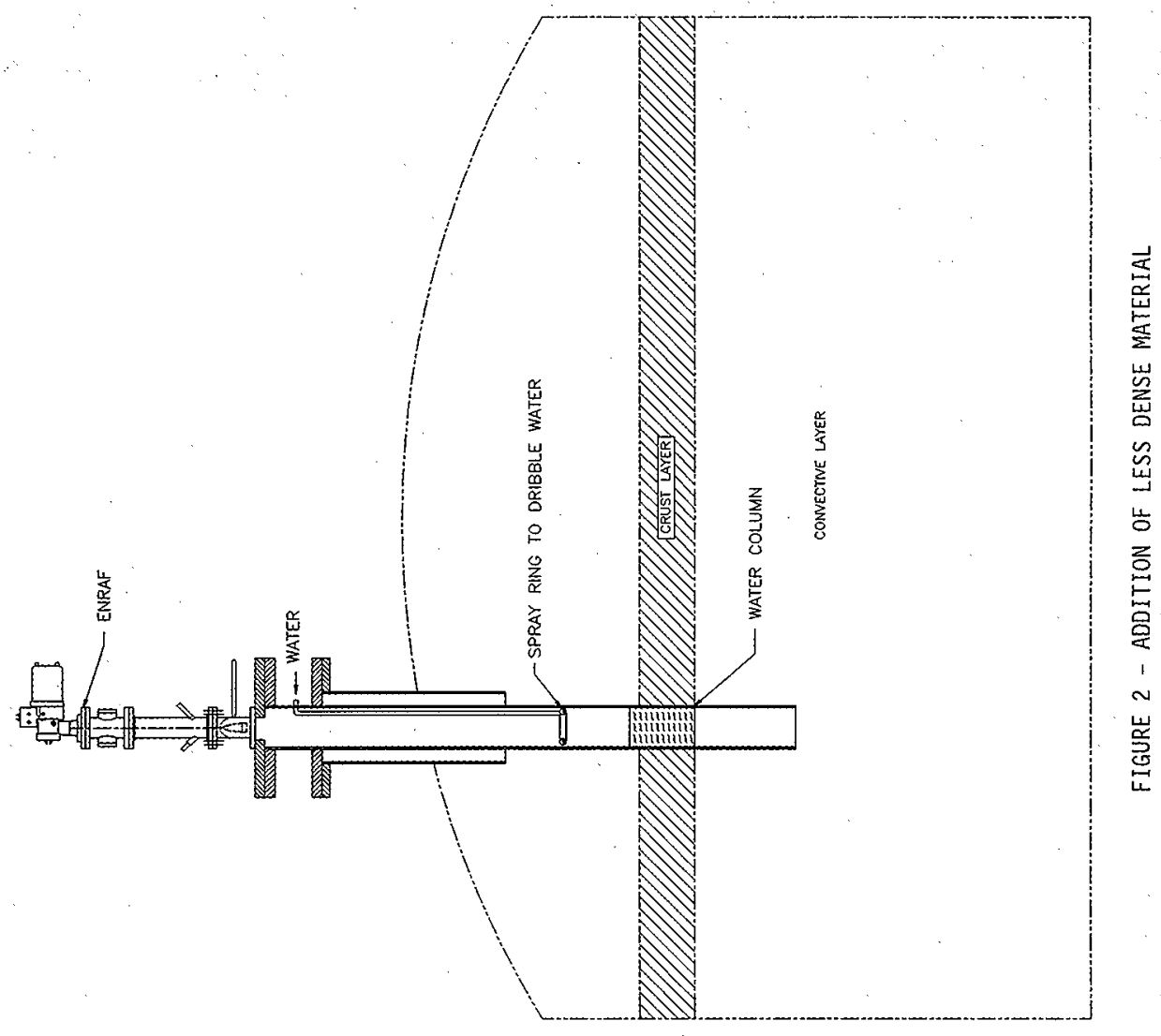


HNF-3374, Rev 0

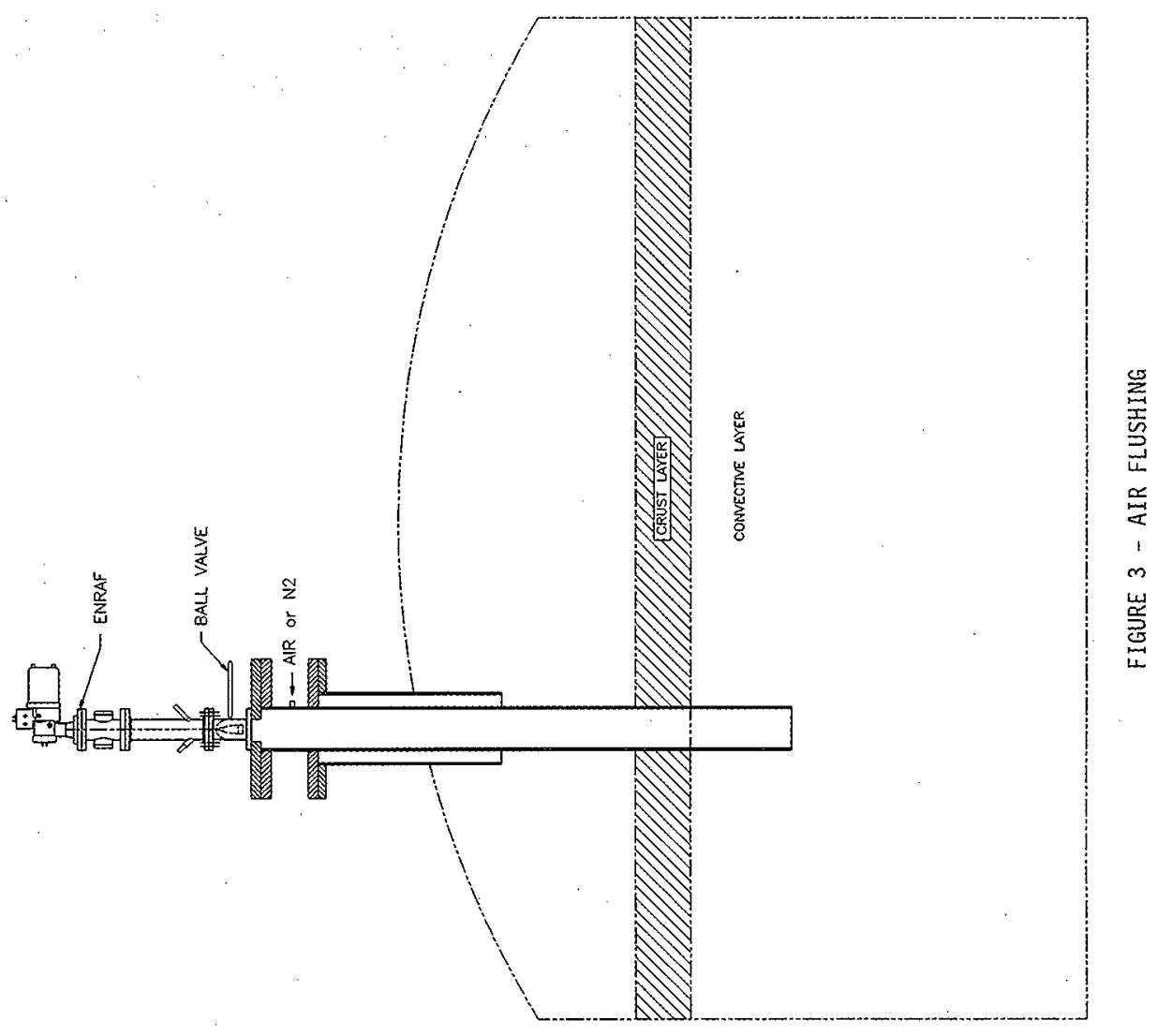


HNF-3374, Rev 0

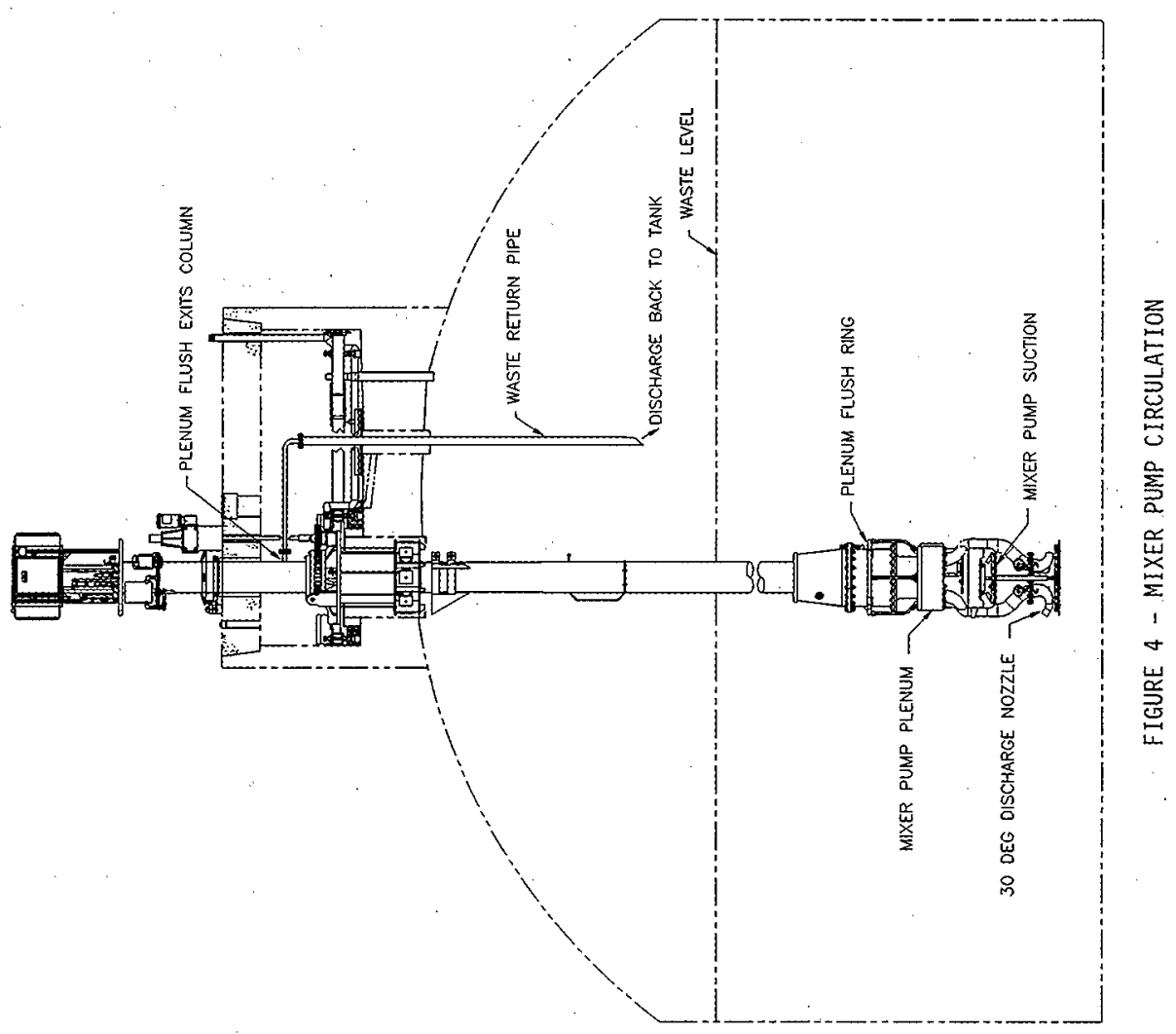


HNF-3374, Rev 0

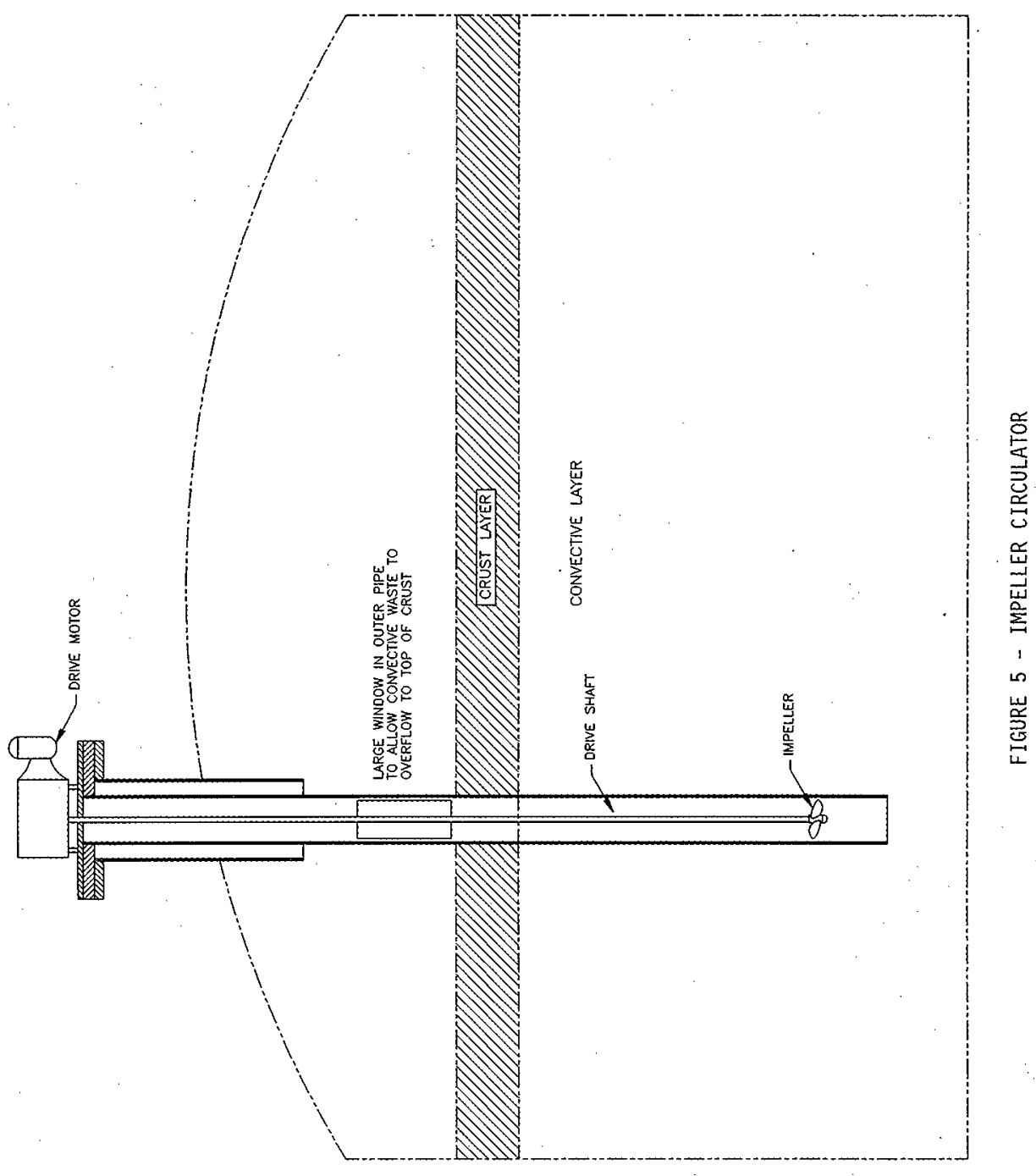


HNF-3374, Rev 0

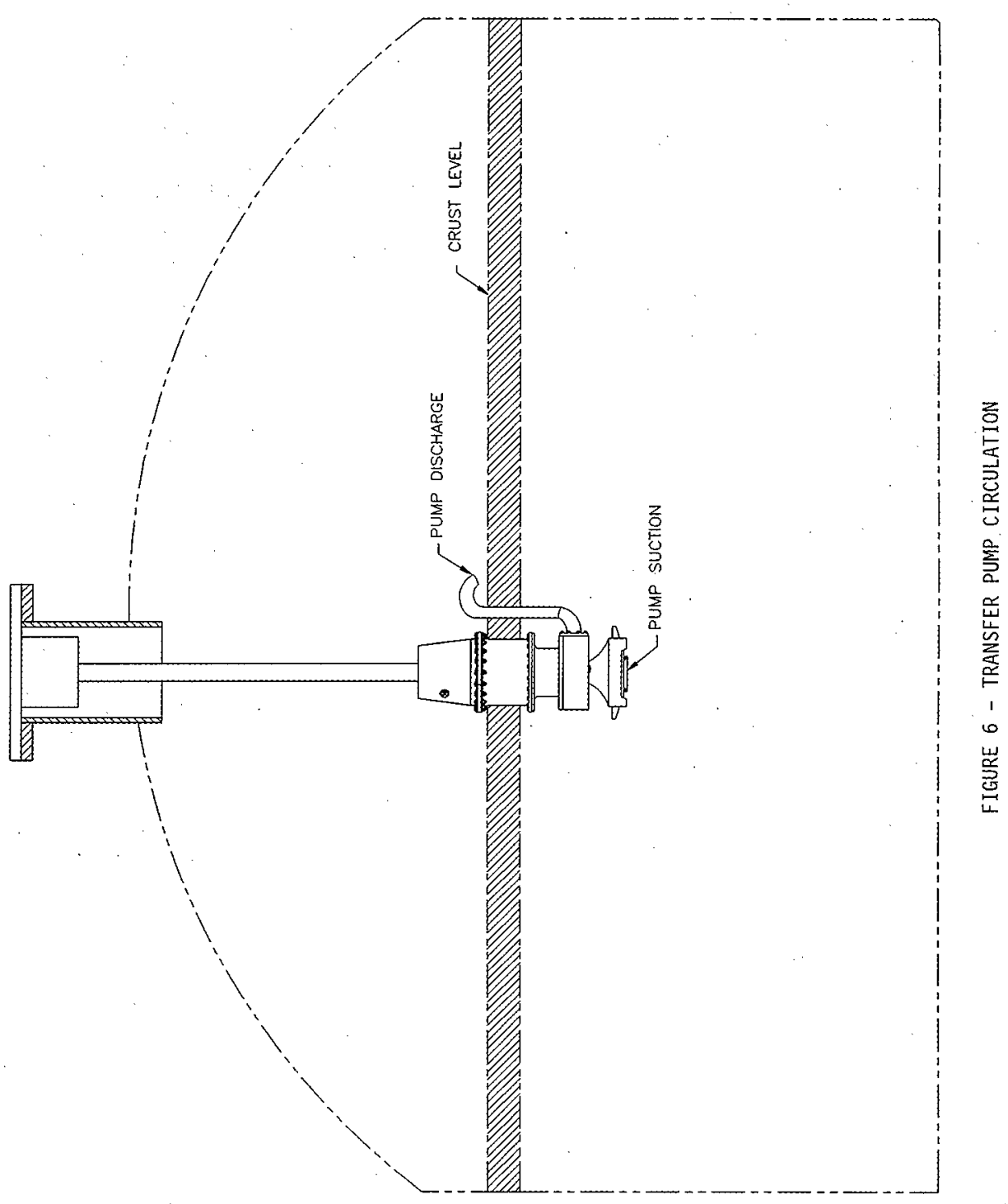


HNF-3374, Rev 0

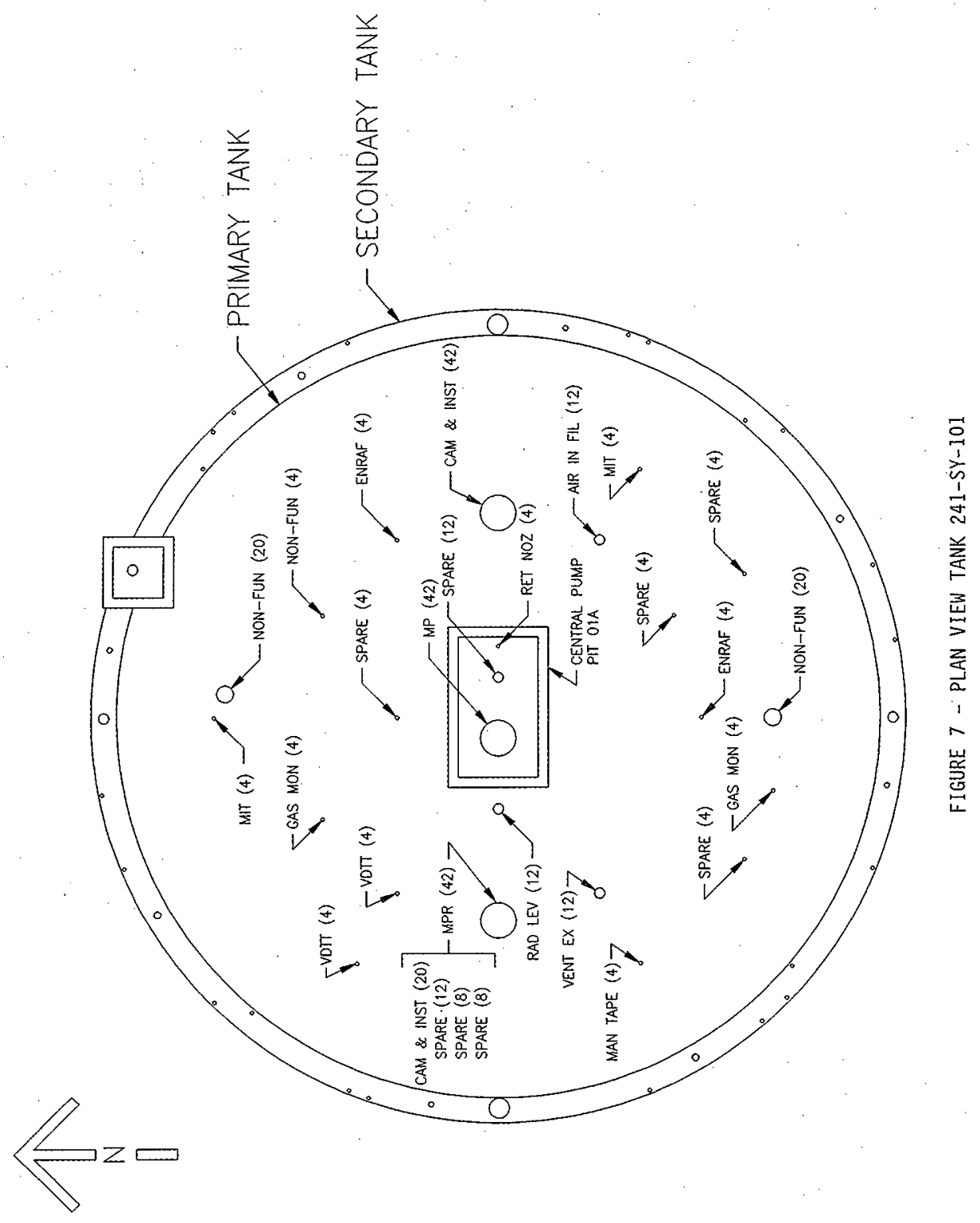




\section{APPENDIX B}

PREFERRED ALTERNATIVE COST AND SCHEDULE 


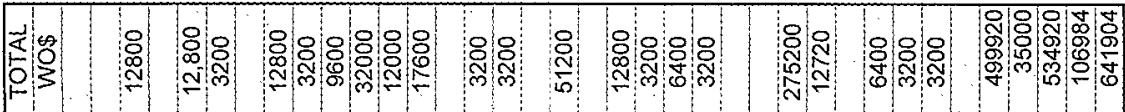

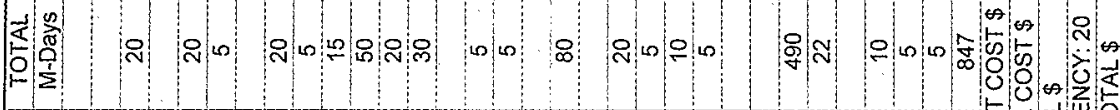
: 5 :

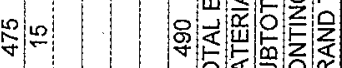

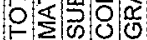

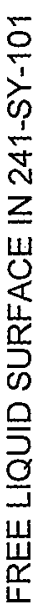

c) की

o:

$\sum_{-1}^{0} \frac{a}{2}$

아요

只

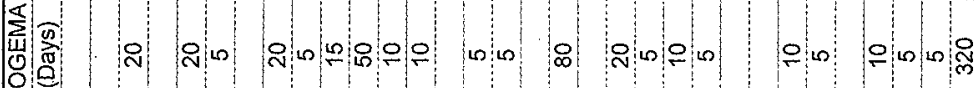

0

$\infty$

r.

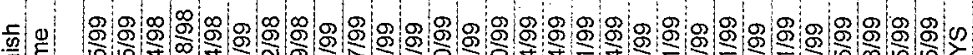

E E W W

NัW

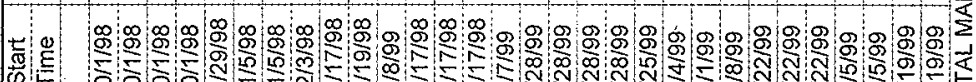

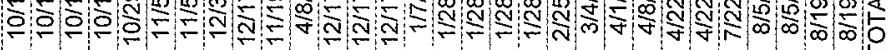

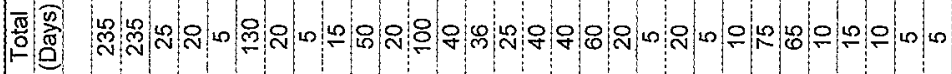

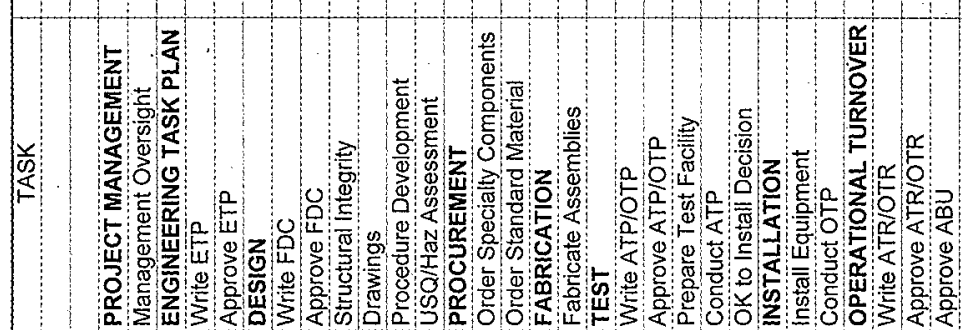


HNF-3374, Rev 0

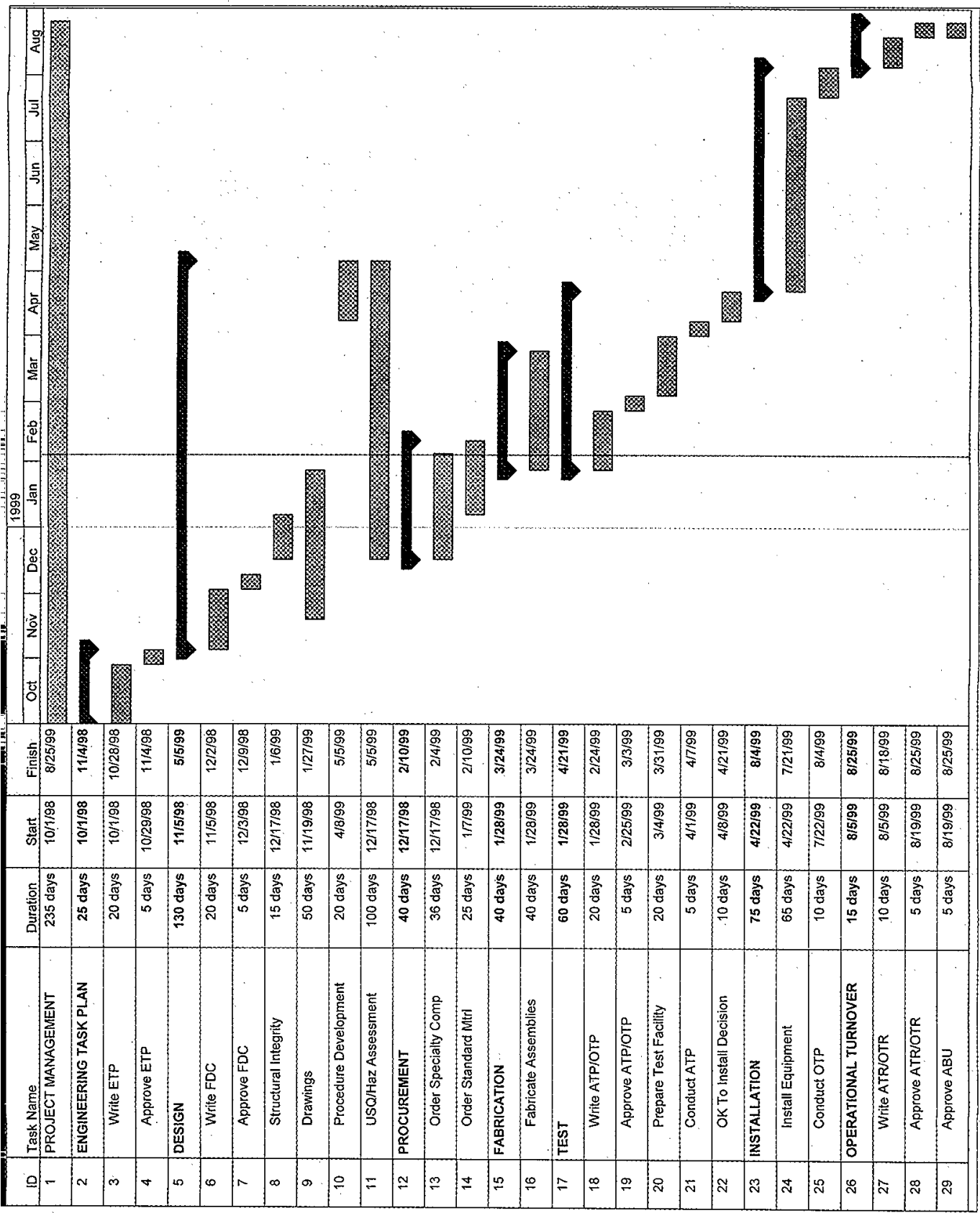

